Martina Kekule, Vojtěch Žák

Czech Republic

Zuzana Ješková, Katarína Kimák@á

Slovakia

\title{
Gender Differences when Assessing the Impact of Inquiry-Based Science Education
}

DOI: $10.15804 /$ tner.2017.48.2.08

\begin{abstract}
The study focuses on the implementation of inquiry-based science education (IBSE) within the 7FP ESTABLISH project and its impact on pupils. The project included the creation of education units and realization of courses for teachers with the goal of educating teachers on IBSE. This was then followed by the implementation of IBSE education units into the teaching schedule of teachers who completed the respective courses. The impact of IBSE on pupils was evaluated using adopted and adjusted evaluation tools. The evaluation focused on the impacts on pupils' intrinsic motivation for learning natural sciences, understanding the importance of natural sciences for society and pupils' epistemological beliefs. The study discusses the results obtained in Slovakia and focuses especially on gender differences.
\end{abstract}

Keywords: inquiry-based science education (IBSE), evaluation, questionnaire, ESTABLISH project

\section{Introduction}

Inquiry-based science education was at the forefront of the interests of the Europe-based ESTABLISH project. In general, inquiries in the area of science can be divided into two groups (Champagne, Kouba, Hurley, 2000): inquiries made in real laboratories and science-related inquiries carried out by pupils or adults interested in science. These two types of scientific inquiries differ especially in 
their purpose: whereas the purpose of the first one is to expand our understanding of the world around us, the goal of the second one is to understand already existing knowledge, e.g., to make correct decisions in life. The goal of this project (financed within the $7^{\text {th }}$ Framework Programme of the EU, no. 244749), which of course supports the second type of inquiries, was the dissemination of this method in secondary schools in Europe. During the execution of the project, nearly 20 collections of methodological materials for education units intended for teachers of natural sciences (further NS) were created. The goal of the project was not only to support teachers during the implementation of the inquiry-based method into standard education, but also to support cooperation with other subjects which can actively participate in the education process based on this method. Specifically, this includes, e.g., employees and individuals active in areas of technology, scientific institutions, education-related policies, research on education and, of course, parents. Evaluating the impact of the project on pupils focused on the following areas:

- development of students' analytical skills and their learning processes,

- impacts on their intrinsic motivation for learning NS (with respect to various factors such as gender, cultural environments, etc.),

- their understanding and acknowledgment of the importance of science and technology for our society,

- impacts on their choice of career in NS.

The paper presents selected results from the above-specified areas with respect to gender, which has been shown to be an important factor related to various attitudes of pupils towards science and technology (e.g., Sjøberg\&Schreiner, 2006; Lavnen et al., 2006; Jenkins, 2006; Osborne et al., 2003). Osborne et al. (2003) even claim that gender is one of the most important variables in this respect. Kahle\&Lakes (1983), e.g., list a specific difference which is particularly important for the inquirybased method - that girls are significantly less interested in watching or realizing experiments, and further work has confirmed these findings (Jones et al., 2000).

When proposing our research, we specifically targeted the following questions: Do the realized activities motivate girls and boys differently? In this respect, we were interested mainly in intrinsic motivation. Does the realization have an impact on the understanding of NS by pupils? And if yes, is there a difference between girls and boys? Do pupils' attitudes towards NS differ before and after the realization of project activities? And if yes, are there differences between boys and girls in this respect? Two questionnaires were created to ascertain the impacts on students: the first one focused on intrinsic motivation and other variables which are considered to be positive predictors of intrinsic motivation, while the second one focused especially on the evaluation of attitudes to NS and choice of vocation 
in NS. Regarding impacts on pupil cognitive skills, as previously observed by Black et al. (2006), it is possible to evaluate a range of aspects including, e.g., knowledge of the world around us, logical thinking, conceptual understanding, observation, asking questions and experimental skills. Due to the fact that the realized project was not a scientific one and hence the teachers could not spend too much time collecting feedback, evaluating the impacts on pupils with respect to their cognitive skills was limited to only a single aspect, specifically their understanding of how NS work (how scientists create and verify hypotheses, etc.) including also their ideas about learning NS. A more in-depth theoretical overview and description of the used methodology, including a description of individual questionnaires, is available in the proceedings of the ESERA conference in 2013: Kekule, M. et al. Inquiry-based science education and collecting evidence about its impact on students (Establish project approach).

\section{Methodology}

\section{Tools and procedures of research}

Various methodological approaches can be used to evaluate the impacts of the project on pupils - either approaches typically used when evaluating the inquiry-based teaching method or generally focusing on the evaluation of pupil education. Based on Champagne et al. (2000), the inquiry-based work of pupils has several phases and the process takes a relatively large amount of time to finish; this needs to be taken into account when designing the evaluation methods and tools. Qualitative methodological approaches provide a deeper insight into the teaching and education processes, which is important, notably, when students were taught using this method only for a short time interval, e.g., one class. On the other hand, due to the international nature of the project, this methodological approach requires the realization of translations both when obtaining data and during their processing, which may lead to significant problems with respect to the validity of the research. Quantitative methodological approaches in this case offer better means of verifying the data collection process, and this was the main reason why the latter method, and specifically a questionnaire with closed questions, was chosen for the realization of this research.

From the methodological perspective, the solution of research problems was carried out using the quantitative approach. Regarding the specific design, this basically constituted an experiment whereas data were collected with the use of questionnaires. 
To ascertain the impacts of project-based teaching on pupils, two questionnaires (Q), based on existing and internationally verified tools, were created. Q1 is partially based on the Intrinsic Motivation Inventory (IMI, 2013), which builds on the self-determination theory formulated by Ryan \& Deci (2000). The goal of this questionnaire was to evaluate pupils' interest and their perceived choices/ options in inquiry-based education based on the proposed methodological sheets. Another monitored factor was pupils' assessment of the perceived usefulness of the performed activities. The conclusion of the questionnaire was a part taken from the CLES questionnaire (Taylor et al., 1994), focusing on the communication of pupils during lessons. Q2 targeted pupils' attitudes to NS and technologies and also their ideas of how NS work. This questionnaire included a part from the Rose questionnaire (2015) and from EBAPS (Elby et al., 2011). Q1 was administered to pupils after each learning unit (henceforth LU). Q2 was given in the form of a pre-test and post-test; in other words, it was given to pupils before the realization of the block of IBSE LUs, and then after the end of the realization of the project in the given class. Specifically, to complete the post-test pupils had to have completed at least three LUs given by the above-specified method. Both questionnaires were prepared in versions for lower secondary (12-15 years of age) and upper secondary (16-19 years of age) school pupils.

\section{Sample of respondents}

Between October 2011 and February 2013, Slovak lower and USSs taught in experimental courses based on documents in the ESTABLISH project which implement IBSE. These LUs were run by teachers who completed the four-day course dedicated to IBSE. Between November 2011 and February 2012, 50 teachers of natural science subjects (physics, chemistry and biology) were trained within a 12-hour-long course. This was followed up by these teachers implementing the teaching units described within the ESTABLISH project, in various scopes. The first lessons were considered to be pilot lessons, allowing for obtaining the first feedback from both the pupils and teachers; the questionnaires used to obtain feedback from the pupils were also adjusted based on these. IBSE implementation and its impact on pupils was the focus of experimental teaching, which took place from February 2012 (Table 1). The LUs implemented during experimental teaching belonged to the subjects of Sound (physics) and of Water in the Life of Humans (biology). All activities emphasized pupil independent learning supported by worksheets, which were to help the pupils make inquiries of various difficulty. Activities were managed by teachers, who formulated problems/questions and the subsequent solutions to these problems/questions were based on the pupils' 
independent activities in groups in a lab. The pupils worked based on the instructions in worksheets, whereas the teacher coordinated the activities realized by the pupils. By asking suitable questions, the teachers supported both pupil-teacher and pupil-pupil discussion. Activities predominantly focused on the development of skills associated with the planning of experiments, collection, processing and analysis as well as interpretation of data and formulation of conclusions. After the end of an activity, the pupils gave the teacher completed worksheets, the important role of which was represented by the formulation of conclusions from the activity.

Table 1. Number of pupils who completed the questionnaire

\begin{tabular}{llccc}
\hline Subject & \multicolumn{1}{c}{ Topic } & School & $\begin{array}{c}\text { No. of re- } \\
\text { spondents -Q1 }\end{array}$ & $\begin{array}{c}\text { No. of re- } \\
\text { spondents -Q2 }\end{array}$ \\
\hline Physics & Sound & USS & 1386 & 211 \\
\hline Biology & Water in the & USS & 270 & 88 \\
\cline { 2 - 5 } & Life of Humans & LSS & 136 & 53 \\
\hline
\end{tabular}

Q1 was completed by a sample of 1792 pupils from USSs (1656) and LSSs (136). Q2 had a sample of 352 pupils, out of whom 299 were from USSs and 53 were from LSSs. More detailed information about the sample of pupils is provided in Tables 2 and 3. The majority of the pupils who completed the questionnaires for USSs (type A) were between 16 and 17 years of age; the typical age of pupils who completed the questionnaire for LSSs (type B) was 12 and 13.

Table 2. Respondents of Qs $1 \mathrm{~A}$ and $1 \mathrm{~B}$ - division by gender

\begin{tabular}{lcccc}
\hline & \multicolumn{2}{c}{ Q1 A } & \multicolumn{2}{c}{ Q1 B } \\
\hline \multicolumn{1}{c}{ Gender } & Count & Percentage & Count & Percentage \\
\hline Girls & 829 & 50.1 & 62 & 45.6 \\
\hline Boys & 827 & 49.9 & 74 & 54.4 \\
\hline Total & 1656 & 100.0 & 136 & 100.0 \\
\hline
\end{tabular}

Table 3. Respondents of Qs $2 \mathrm{~A}$ and $2 \mathrm{~B}$ - division by gender

\begin{tabular}{lcccc}
\hline & \multicolumn{2}{c}{ Q2 A } & \multicolumn{2}{c}{ Q2 B } \\
\hline \multicolumn{1}{c}{ Gender } & Count & Percentage & Count & Percentage \\
\hline Girls & 171 & 57.2 & 26 & 49.1 \\
\hline Boys & 128 & 42.8 & 27 & 50.9 \\
\hline Total & 299 & 100.0 & 53 & 100.0 \\
\hline
\end{tabular}


From Tables 2 and 3 it is clear that the samples of pupils are gender-balanced, with a very slight dominance of the boys for Q1 B and the girls for Q2 A.

\section{Reliability of questionnaire measurements}

The properties of the used evaluation tools (questionnaires) imply that all the items related to pupil intrinsic motivation (Q1) can be divided into three groups dimensions. The items belonging to a certain dimension are very similar. ${ }^{1}$ Based on this factor, it is possible to determine whether the respondents actually evaluated the items (given statements), or whether they entered random answers. In relation to the above, the questionnaire also includes so-called reverse items. For instance, the direct item "The carried out activities were fun for me" was supplemented by the reverse item "I think that the activities were very boring" in the same dimension. If the responsible respondent provides a positive answer to the direct item, we expect the reverse item to have a negative answer, and vice-versa. The Pearson correlation coefficient was used to determine this characteristic of consistency (or, in general, reliability) of the measurement.

The values of the correlation coefficient for the interest/entertainment dimension ranged between 0.69 and 0.82 for the pair of direct items and from -0.52 to -0.59 for the pair of direct and reverse items. For the opportunity dimension, the range was 0.53 to 0.72 and -0.30 to -0.42 respectively. For the value/usefulness dimension, the range was 0.50 to 0.77 (this dimension did not include reverse items).

Based on the carried out statistical analysis, it was also discovered that all the correlation coefficients were statistically significant $(p<0.05)$. These findings imply that the measurements resulting from the given questionnaire are reliable, since the respondents repeatedly entered the same or very similar opinions.

\section{Research findings and discussion ${ }^{2}$}

This part presents the obtained results, always separately for each of the questionnaires. First, we present the results of Q1, which focused especially on the pupils' intrinsic motivation. This is followed by the results of Q2, which focused

1 Individual items belonging to a given dimension are specified in IMI (2013), available at http://www.selfdeterminationtheory.org/intrinsic-motivation-inventory/

2 Due to the fact that there are several research findings, for the sake of clarity this section deals with both the presentation of scientific findings and their discussion. 
on the pupils' attitude to NS, their career choices in this area and the pupils' ideas about how NS work.

\section{Intrinsic motivation (Q1)}

Q1 measured the pupils' intrinsic motivation to participate in the carried out activities - inquiry-based education. The presented data from the questionnaire are summarized for individual dimensions (interest/entertainment, opportunity, value/usefulness). The average score obtained for each dimension is presented in Table 4.

Table 4. Average relative score (in \%) for individual dimensions ${ }^{3}$

\begin{tabular}{lccccccccc}
\hline & \multicolumn{7}{c}{ Score in \% } \\
\hline & All & Girls & Boys & $\begin{array}{c}\text { Difference } \\
\text { girls x boys }\end{array}$ & All & Girls & Boys & $\begin{array}{c}\text { Difference } \\
\text { girls x boys }\end{array}$ \\
\hline & 69.20 & 72.27 & 66.11 & yes & 79.00 & 83.29 & 75.41 & yes \\
\hline $\begin{array}{l}\text { Interest/Enjoy- } \\
\text { ment }\end{array}$ & & & & & & & & \\
\hline Perceived choice & 59.54 & 61.52 & 57.56 & yes & & Data was not collected. \\
\hline Value/Usefulness & 68.51 & 70.96 & 66.07 & yes & 75.51 & 79.57 & 72.11 & yes \\
\hline
\end{tabular}

Gender differences were identified for all the dimensions for both age groups (A for LSSs and B for USSs). The girls were more positive in their assessment, i.e., their scores in intrinsic motivation and other dimensions representing positive predictors of intrinsic motivation were higher. Detailed results documenting the statistical evaluation using the Kolmogorov-Smirnov (K-S) test in the Statistica program are presented in Table 5 . For illustration, we are only presenting the data for Q A, i.e., the questionnaire distributed to the USS pupils.

The second part of Q1 asked the pupils to express their opinion on the perceived communication options during the lessons. For instance, they were asked whether they had the opportunity to speak to other pupils, whether they had the opportunity to explain their own ideas to them, etc. Their opinions about the statements were entered in the form of a five-point scale ranging from 1 (almost never) to 5 (almost always). The K-S test identified a difference in the evaluation of item no. 4 for the USS pupils; specifically, the girls said that they ask other pupils to express their ideas more often than the boys.

\footnotetext{
${ }^{3}$ Statistical significance of differences was determined based on the K-S test of equality (cf., also Tables 5, 6, 7 and 8).
} 
Table 5. Gender differences in the evaluation of dimensions (the average is calculated from the total score)

\begin{tabular}{lccccccc}
\hline \multirow{2}{*}{ Dimension } & \multicolumn{7}{c}{ Kolmogorov-Smirnov Test } \\
\cline { 2 - 8 } & $\begin{array}{c}\text { Max. } \\
\text { neg. dif- } \\
\text { ference }\end{array}$ & $\begin{array}{c}\text { Max. } \\
\text { pos. dif- } \\
\text { ference }\end{array}$ & $\begin{array}{c}\text { p- } \\
\text {-value }\end{array}$ & $\begin{array}{c}\text { Mean } \\
\text { Group 1 } \\
\text { GIRL }\end{array}$ & $\begin{array}{c}\text { Mean } \\
\text { Group 2 } \\
\text { BOY }\end{array}$ & $\begin{array}{c}\text { Std. Dev. } \\
\text { Group 1 } \\
\text { GIRL }\end{array}$ & $\begin{array}{c}\text { Std. Dev. } \\
\text { Group 2 } \\
\text { BOY }\end{array}$ \\
\hline $\begin{array}{l}\text { Interest/Enjoy- } \\
\text { ment }\end{array}$ & -0.0036 & 0.1729 & $\mathrm{p}<0.001$ & 40.47 & 37.02 & 10.46 & 10.73 \\
\hline $\begin{array}{l}\text { Perceived } \\
\text { choice }\end{array}$ & -0.0192 & 0.1668 & $\mathrm{p}<0.001$ & 34.45 & 32.23 & 10.37 & 9.67 \\
\hline $\begin{array}{l}\text { Value/Useful- } \\
\text { ness }\end{array}$ & -0.0012 & 0.1498 & $\mathrm{p}<0.001$ & 44.70 & 41.62 & 10.82 & 10.57 \\
\hline
\end{tabular}

\section{Discussion:}

Based on the results of Q1, it is clear that both the girls and boys had a positive score in the area of intrinsic motivation for inquiry-based LUs. The girls were more positive than the boys in all the monitored dimensions. The interpretation of the results related to communication during the carried out activities may be based on two aspects: frequency of communication and preferred type of communication. Within each item, it was the group of girls that tended towards more frequent communication, however no statistically relevant difference was observed aside from the above-mentioned item 4 . The difference for item 4 can be interpreted in at least two ways. First, girls are perhaps less confident in the area of NS, and that is why they are more likely to ask their classmates for explanation. Second, it is possible that girls are less shy than boys to ask for help when they do not understand a problem. These hypotheses may be an interesting topic for further research.

\section{Attitudes of pupils to NS, natural science subjects and career choice in the area of NS and technologies (Q2)}

Q2 contained two parts focusing on the pupils' attitudes to NS (part 1 and 5), and also a part focusing on the pupils' ideas about the functioning of NS (the middle part of the questionnaire). This questionnaire allowed for real evaluation of the impact of the project on the pupils, and was given in the form of a pretest and a posttest, i.e., before the inquiry-based education started and after the project activities ended in a given class.

The following results are thus based on both the results of the questionnaire before the project (the pretest) and the differences obtained by comparing the 
pretest and the posttest. The former results are used to ascertain the state of the situation before the project began, and to compare potential differences between the girls and boys. The latter comparison provides an evaluation of the project's impacts and is realized in two variants: jointly for all the pupils, and separately for the girls and for the boys (in either case by comparing their responses in the pretest and posttest).

Analysis of the pretest data showed a statistically significant difference between the boys and the girls only in the evaluation of four items. Detailed results are listed in Table 6 and Table 7. The statements the pupils agreed or disagreed with are items no. 1 and 6 in Table 7, and two more statements: The things that I learn in science at school will be helpful in my everyday life (girls agree more than boys.), The benefits of science are greater than the harmful effects it could have (girls do not agree whilst boys do.); the pupils responded by using a four-point Likert scale.

Table 6. Gender differences in the average evaluation of four items in the pretest (average calculated from the total obtained score $)^{4}$

\begin{tabular}{|c|c|c|c|c|c|c|c|}
\hline \multirow[b]{2}{*}{$\begin{array}{l}\text { Item } \\
\text { No. }\end{array}$} & \multicolumn{7}{|c|}{ Kolmogorov-Smirnov Test } \\
\hline & $\begin{array}{l}\text { Max. neg. } \\
\text { difference }\end{array}$ & $\begin{array}{l}\text { Max. pos. } \\
\text { difference }\end{array}$ & p-value & $\begin{array}{l}\text { Mean } \\
\text { Group } 1 \\
\text { GIRL }\end{array}$ & $\begin{array}{c}\text { Mean } \\
\text { Group } 2 \\
\text { BOY }\end{array}$ & $\begin{array}{l}\text { Std. Dev. } \\
\text { Group } 1 \\
\text { GIRL }\end{array}$ & $\begin{array}{c}\text { Std. Dev. } \\
\text { Group } 2 \\
\text { BOY }\end{array}$ \\
\hline I & 0.0000 & 0.1744 & $\mathrm{p}<0.025$ & 2.81 & 2.59 & 0.83 & 0.92 \\
\hline II & -0.0141 & 0.1626 & $\mathrm{p}<0.050$ & 2.95 & 2.74 & 0.75 & 0.92 \\
\hline III & -0.4663 & 0.0000 & $\mathrm{p}<0.001$ & 1.62 & 2.61 & 0.78 & 1.04 \\
\hline IV & -0.1620 & 0.0000 & $\mathrm{p}<0.05$ & 2.46 & 2.77 & 0.71 & 0.76 \\
\hline
\end{tabular}

Analysis of data obtained by the pretest and posttest revealed several differences in the evaluation of items between the girls and boys. Specific differences, including a formulation of the items, are shown in Table 7.

Table 7. Statistically significant differences in evaluation (comparison of posttest and pretest)

\footnotetext{
${ }^{4}$ Only items with a statistically significant difference in their evaluation are listed. Scale: 1 - I disagree to 4 - I agree. The average value of the scale is hence 2.5. Items belong to the part assessing the pupils' attitude towards natural sciences.
} 


\begin{tabular}{|c|c|c|c|c|}
\hline \multirow{2}{*}{$\begin{array}{l}\text { Item } \\
\text { No. }\end{array}$} & \multirow[t]{2}{*}{ Item } & \multicolumn{2}{|c|}{$\begin{array}{l}\text { Difference in pre- } \\
\text { and post- test }\end{array}$} & \multirow[t]{2}{*}{ Specification } \\
\hline & & Girls & Boys & \\
\hline 1 & School science is a difficult subject. & yes & yes & $\begin{array}{l}\text { Girls agree more. Boys } \\
\text { agree more. }\end{array}$ \\
\hline 2 & $\begin{array}{l}\text { School science has made me more } \\
\text { critical and sceptical. }\end{array}$ & yes & yes & $\begin{array}{l}\text { Girls disagree less. } \\
\text { Boys disagree less. }\end{array}$ \\
\hline 3 & $\begin{array}{l}\text { School science has increased my } \\
\text { curiosity about things we cannot yet } \\
\text { explain. }\end{array}$ & yes & no & Girls agree more. \\
\hline 4 & $\begin{array}{l}\text { School science has increased my } \\
\text { appreciation of nature. }\end{array}$ & no & yes & $\begin{array}{l}\text { Boys shifted from slight } \\
\text { disagreement to slight } \\
\text { agreement. }\end{array}$ \\
\hline 5 & $\begin{array}{l}\text { I would like to have as much science } \\
\text { as possible at school. }\end{array}$ & yes & no & Girls disagree less. \\
\hline 6 & I would like to get a job in technology. & yes & no & Girls disagree more. \\
\hline 7 & $\begin{array}{l}\text { Science and technology are important } \\
\text { for society. }\end{array}$ & no & yes & Boys agree less. \\
\hline 8 & $\begin{array}{l}\text { Thanks to science and technology, } \\
\text { there will be greater opportunities for } \\
\text { future generations. }\end{array}$ & yes & yes & $\begin{array}{l}\text { Girls agree less. Boys agree } \\
\text { less. }\end{array}$ \\
\hline 9 & $\begin{array}{l}\text { New technologies will make work } \\
\text { more interesting. }\end{array}$ & yes & no & Girls agree more. \\
\hline 10 & Science and technology help the poor. & no & yes & Boys disagree less. \\
\hline 11 & $\begin{array}{l}\text { A country needs science and technol- } \\
\text { ogy to become developed. }\end{array}$ & yes & yes & $\begin{array}{l}\text { Girls agree less. Boys agree } \\
\text { less. }\end{array}$ \\
\hline 12 & $\begin{array}{l}\text { We should always trust what scientists } \\
\text { have to say. }\end{array}$ & no & yes & Boys disagree less. \\
\hline 13 & $\begin{array}{l}\text { Scientific theories develop and change } \\
\text { all the time. }\end{array}$ & yes & no & Girls agree less. \\
\hline
\end{tabular}

Both groups, i.e., the boys and girls, who experienced inquiry-based education showed changes in the average evaluation of items 1,2,8 and 11. However, for the latter two items, the pupils agreed with the claims less strongly/frequently in the posttest than in the posttest.

The girls expressed different levels of agreement with items 3, 9 and 5, which may indicate a positive impact of the project on girls. For the last mentioned item, even though the girls still rather disagreed with the statement, they did so less strongly/frequently than before, and hence this can be considered to be a positive 
development. The average evaluation of certain statements (specifically items 6 and 13), however, also had a change towards a more negative attitude.

The boys expressed different levels of agreement with items 4, 10 and 12, which may indicate a positive impact of the project on boys. Similarly as for the case of the girls, for the last two mentioned items, the boys still rather disagreed with the statements but they did so less strongly/frequently than before, and this can be therefore considered to be a positive development. Furthermore, the boys agreed less with the statement of item 7 in the posttest compared to the pretest.

\section{Discussion:}

When interpreting the girls' results, we can focus our attention to key words in the items where changes of the average evaluation occurred. Specifically these were the words of curiosity and new technologies. It is probable that these aspects could positively influence the girls' attitude to NS. The presented results provide a good basis for further, more in-depth research, specifically using qualitative research methods. On the other hand, the boys had different results in the average evaluation of the items associated with society and authority. Within the pretest, the boys disagreed with the statement that science and technology help the poor. However, they do consider science and technology to be important for society. This could point towards the perception of science and technology as merely being a set of expensive devices which are not available in developing countries.

\section{Epistemological beliefs (Q2)}

The following results are related to the pupils' epistemological ideas about NS. As specified above, the items ascertaining the impact of the project on the pupils in this area were for the purposes of the EBAPS questionnaire, grouped into several dimensions; specifically, the pupils' ideas were collected and grouped in the following three dimensions: structure of scientific findings, essence of learning and discovery, and development of scientific knowledge. The results are first presented as a summary for individual dimensions.

Within the pretest, a statistically significant difference $(\mathrm{p}<0.05)$ was identified between the girls and the boys only for the average scores in the dimension of scientific knowledge. This dimension, which is based on the authors of the EBAPS questionnaire, "determines where the student's ideas lie on the scale between two extremes: absolutism (the idea that all scientific knowledge is "fixed, written in stone") on one hand, and extreme relativism (not distinguishing between argumentation based on proof and opinions) on the other hand." The girls obtained a higher average score than the boys in this dimension. This difference is apparently 
most caused by the item which asked the pupils to express their (dis)agreement with the statement: "When it comes to controversial topics such as which foods cause cancer, there is no way for scientists to evaluate which scientific studies are the best. Everything's up in the air!" The girls disagreed with this claim more than the boys. More detailed results of the analysis of data obtained from the questionnaire given before the project activities are presented in Table 8 .

Table 8. Gender differences in the pretest scores (dimensions by EBAPS).

\begin{tabular}{lccccccc}
\hline & \multicolumn{7}{c}{ Kolmogorov-Smirnov Test } \\
\cline { 2 - 8 } Dimension & $\begin{array}{c}\text { Max.neg. } \\
\text { difference }\end{array}$ & $\begin{array}{c}\text { Max.pos. } \\
\text { difference }\end{array}$ & p-value & $\begin{array}{c}\text { Mean } \\
\text { Group 1 } \\
\text { GIRL }\end{array}$ & $\begin{array}{c}\text { Mean } \\
\text { Group 2 } \\
\text { BOY }\end{array}$ & $\begin{array}{c}\text { Std.Dev. } \\
\text { Group 1 } \\
\text { GIRL }\end{array}$ & $\begin{array}{c}\text { Std. } \\
\text { Dev. } \\
\text { Group }\end{array}$ \\
\hline $\begin{array}{l}\text { Structure of } \\
\text { knowledge }\end{array}$ & -0.0383 & 0.0539 & $\mathrm{p}>0.10$ & 13.08 & 13.09 & 3.62 & 3.66 \\
\hline $\begin{array}{l}\text { Nature of } \\
\text { knowledge }\end{array}$ & -0.0823 & 0.0263 & $\mathrm{p}>0.10$ & 13.25 & 13.43 & 3.34 & 3.43 \\
\hline $\begin{array}{l}\text { Evolving } \\
\text { knowledge }\end{array}$ & -0.0175 & 0.1651 & $\mathrm{p}<0.05$ & 6.27 & 5.67 & 2.48 & 2.20 \\
\hline
\end{tabular}

Differences between average results obtained in the pretest and posttest are sporadic. The only dimension where the average score changed both for the girls and the boys (between the pretest and posttest) is the dimension focusing on the "essence of learning and discovery". The authors characterize this dimension by the following questions: "Does learning science consist mainly in absorbing information? Or, does it rely crucially on constructing one's own understanding by working through the material actively, by relating new material to prior experiences, intuitions, and knowledge, and by reflecting upon and monitoring one's understanding?". Both genders had a lower score in the posttest than in the pretest. The only item which belonged to this dimension where both the girls and boys achieved a higher average score in the posttest is the item which is closely linked to their own experience: "If physics and chemistry teachers gave really clear lectures, with plenty of real-life examples and sample problems, then most good students could learn those subjects without doing lots of sample questions and practice problems on their own." However, in spite of this positive change, the overall average score was very low in all the cases, i.e., nearly zero. Based on the above-specified output, we believe that the project had a very small impact on the pupils' epistemological ideas about NS. 


\section{Conclusion}

The results of the performed analysis can be summarized in the following conclusions:

The pupils had a positive attitude to IBSE, saying that the performed activities were interesting, entertaining and useful. Gender differences were observed in all the three dimensions, whereas the girls were generally more positive in their evaluation.

Regarding communication during lessons, the pupils generally were of the opinion that they had ample opportunity to speak with other pupils about how to solve the presented problems. Statistically significant gender differences were not observed. However, a slight difference was observed in the item "I ask other pupils about how to solve problems", where the girls more strongly agreed with this statement. This could mean that girls are less confident in solving problems in NS or that they are less shy than boys.

Regarding the pupils' attitude to NS and their role in society and the pupils' career tendencies in the area of NS and technology, significant changes were not observed in most items even after the pupils underwent a series of IBSE activities. However, a positive impact on the girls was observed through an increase in their curiosity about things, which remains unexplained. On the other hand, the girls gave negative scores for their interest in the teaching of NS in schools and a career in these areas in the posttest when compared to the pretest.

Regarding the pupils' epistemological beliefs, three dimensions were evaluated: the structure of scientific findings, the essence of learning and discovery, and development of scientific knowledge. If we compare the results of the pretest and posttest, changes are only observed in the second dimension, which asks pupils about how findings in NS are obtained, whether this is based on people' experiences, etc. After the pupils had completed the IBSE LUs, both the girls and boys were more confident about the fact that the interpretation of findings without any practical experience is not sufficient to provide pupils with sufficient understanding of NS. On the other hand, regarding their own ideas and thoughts on the problems and their importance, the pupils marked these as less important in the posttest than in the pretest.

In general, we can conclude that the impacts of IBSE were more positive for the girls than for the boys, whose attitudes and opinions did not dramatically change in the analyzed areas and which remained more or less the same as before the experimental lessons. 
Further discussion could focus on whether we could have predicted the obtained results. To be honest, we expected a more positive impact on the pupils' opinions and beliefs. However, certain national specifics need to be taken into account. Slovakia has been undergoing a school reform since 2008. The Slovak national curriculum puts emphasis on the inquiry-based approach in the teaching of NS, however there is a lack of supporting materials available to teachers for the realization of IBSE. Slovak teachers are still generally not very well educated in this area. Traditional teaching methods are dominant in schools, and these are also preferred by teachers. The sample of teachers that participated in the above-specified research participated in workshops aiming at increasing the knowledge of teachers with IBSE before they implement the selected activities in their own teaching. However, even after taking part in several workshops and even with supporting methodological documents provided within the project (custom-made activities and prepared materials/sheets for teachers and pupils), the teachers still lack the competences required to properly apply IBSE in their teaching. The teachers do try to apply the inquiry-based approach in their lessons, to ask questions and support the independence of pupils, but they often have a tendency to answer the questions themselves and to have a very direct approach in the performed activities. Regarding the pupils themselves, they are also not used to this approach to teaching and often their expectations and active work do not correspond to the teachers' expectations. Pupils often expect the help of the teacher or clear instructions on how to process or what to do. This is related to the fact that traditional teaching methods (based on lectures) dominate in schools, and this is not only the case for the considered natural science subjects. We believe that these are the main reasons why the results did not indicate more significant changes. To obtain more convincing results, teachers need more permanent and systematic professional development, which will support greater applicability of IBSE in teaching, also in more subjects than those considered here. Still, we can say that the above analysis brought an interesting comparison of girls and boys in the perception of IBSE, showing a more positive impact on girls, who seem to have been more influenced by this form of teaching.

\section{References}

Black, P. et al. (2006). Learning how to learn. Research Papers in Education, 2. pp. 119-132 Champagne, A., Kouba, V., Hurley, M. (2000). Assessing Inquiry In Minstrell, J., \& van Zee, E.H. Inquiring into Inquiry Learning and Teaching in Science. New York: American Association for the Advancement of Science. 
Elby, A. et al. (2011, December 5) Epistemological Beliefs for Physical Science - EBAPS. Available from http://www2.physics.umd.edu/ elby/EBAPS/EBAPS_items.htm

ESTABLISH project (2013, August 2). Available from http://www.establish-fp7.eu

Gago, J.M. (2004). Europe needs more scientists. Report by the High Level Group on Increasing Human Resources for S\&T in Europe. Brussels, Belgium: European Commission.

IMI - Intrinsic Motivation Inventory (2013, August 2) Available from http://www.selfdeterminationtheory.org/questionnaires/10-questionnaires/50

Jenkins, E., W. (2006). The Student Voice and School Science Education, Studies in Science Education, 42, pp. 49-89

Kekule, M., Žák, V., Ješková, Z., Kimáková, K., Ganajová, M., Kireš, M. Inquiry-based science education and collecting evidence about its impact on students (Establish project approach), Proceedings of the $10^{\text {th }}$ conference of the ESERA, 2-7 September 2013, Nicosia, Cyprus, In press.

Lavnen, J., Byman, R., Juuti, K., Meisalo, V., Uitto, A. (2006, June 5). Pupil Interest in Physics: A Survey in Finland. Available from http://www.naturfagsenteret.no/tidsskrift/Nordina_205_Lavonen.pdf

ROSE project - The Relevance of Science Education. (2015, January 12) Available from http://roseproject.no./

Ryan, R.M., \& Deci, E.L. (2000). Self-determination theory and the facilitation of intrinsic motivation, social development, and well-being. American Psychologist, 55, pg. 68-78. Available from http://www.selfdeterminationtheory.org/questionnaires/10-questionnaires $/ 50$

Sjøberg, S., Schreiner, C. (2006). How do students perceive science and technology?, Science in School, 1, pp. 66-69

Taylor, P.C., Fraser B.J., \& White, L.R. (1994). CLES: An instrument for monitoring the development of constructivist learning environments. Paper presented at the annual meeting of the American Educational Research Association, New Orleans. 